\title{
A Framework for Collaborative Innovation to Facilitate E-Health Systems Adoption
}

\author{
Janerose Nyamu, Rebecca De Coster, Syakirah Mohamad Taib \\ College of Engineering, Design and Physical Sciences \\ Brunel University, London, UK
}

\begin{abstract}
The promise of telemedicine is great as observed in developed countries. However, its adoption in developing countries has been very slow. Extant literature on healthcare technological innovation indicates that organization collaboration can expedite the adoption of telemedicine especially in developing countries. The Kenyan government approved telemedicine (use of ICT to overcome geographical barriers and increase access to health care services) as a strategic approach of improving healthcare delivery especially in the marginalized areas of the country. However, the adoption of telemedicine is further hindered in developing countries by the fact that the cost of implementing telemedicine technology is deemed to be high and the resources needed are scarce especially in the public sector. This study employed a conceptual research framework to examine organizational factors that may influence organization collaboration in facilitating telemedicine adoption in developing countries. A questionnaire survey was conducted in 50 hospitals located in Eastern Kenya. The findings of this research revealed that Kenyan hospitals may enhance their ability to adopt telemedicine by affiliating with other organizations. Organization affiliation was found to significantly influence organizational resources, organization innovation acceptance, organization innovation capacity, organization agility and collaborative innovation aspects.
\end{abstract}

\section{Introduction}

A great challenge face the healthcare sector globally especially in the management of chronic and multiple diseases [1]. However, use of Information and Communication Technologies (ICT) has bridged the gap especially in the exchange of medical information from one site to another. Aided by high capacity digital networks, powerful computer hardware and software as well as high resolution digital image compression, the healthcare sector has been greatly transformed in areas that have adopted the technologies [2].
To explain the phenomenon, the term telemedicine was coined by Thomas Bird in 1970s [3] which literally mean healing at a distance. The prefix tele is a Greek word meaning far or distance [4]. Telemedicine is broadly defined as the delivery of health care services where distance is a critical factor by all health care professionals using ICT for the exchange of valid information for diagnosis, treatment and prevention of disease and injuries, research and evaluation, and for the continuing education of health care providers, all in the interests of advancing the health of individuals and their communities [5].

Reference [6] claims that less than half of the population in developing countries has adequate access to healthcare. Poor ICT infrastructure and economic levels has been claimed to contribute to failure in the adoption of telemedicine technology which is believed to bridge the geographical gap between healthcare providers and patients [6]. It is claimed that majority of few medical professional in developing countries are located in urban centers [7]. As a result, patients requiring specialized diagnosis travel to the major towns or cities where the specialized health care professionals are located which is expensive and inconveniencing to the patients. Besides, the waiting time is claimed to be very high. Telemedicine scholars claim that the adoption of telemedicine technology in developing countries will bridge the existing gap [8].

Studies done on telemedicine adoption in developing countries have highlighted that telemedicine projects running in developing countries are mainly grant funded by developed countries [9] and other international nongovernmental organisations [7]. As a result, economic sustainability is a major challenge to telemedicine adoption in these countries [10]. According to the Alma-Ata Declaration in 1978, primary healthcare is essential healthcare based on practical, scientifically sound and socially acceptable methods and technology made universally accessible to individuals and families in the community through their full participation and at a cost that the community and country can afford to 
maintain at every stage of their development. However, it is claimed that healthcare provision in developing countries is still not a priority especially focusing on telemedicine technology [11] which is believed to improve the distribution of healthcare specialties [7].

According to WHO health financing report (2014) and World Bank health expenditure report (2014), developing countries have a lower allocation of the government funds for healthcare when compared to developed countries. Lack of political leaders support to healthcare financing is claimed to influence the amount of finances allocated to healthcare [9]. Also, a country's GDP is considered as an important factor in determining the amount of government resources to be allocated to healthcare [7]. As a result, telemedicine adoption in developing countries has been lagging as shown in Figure 1.

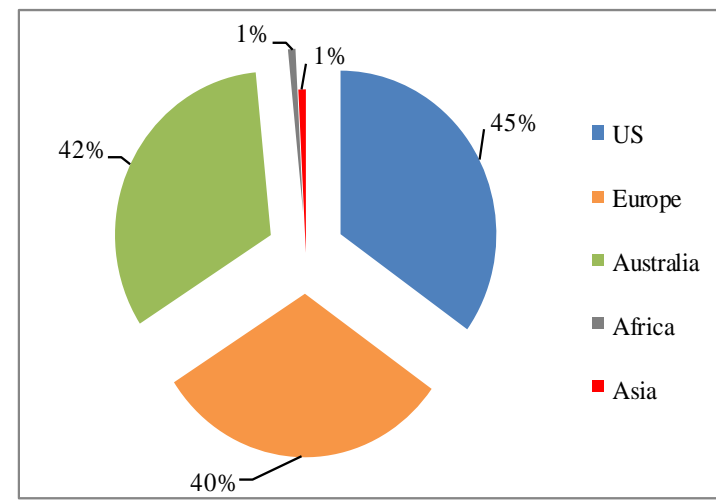

Figure 1. Telemedicine adoption globally (Redrawn from data in Reference 5)

Various studies have highlighted that telemedicine projects require high capital to implement and sustain especially in developing countries [10]. Organization collaboration has been suggested as a solution to this financial barrier [12].

Basing on the extant literature on telemedicine adoption in developing countries, organization collaboration factors and technology innovation factors have been identified to influence the adoption and diffusion of telemedicine. However, researchers have emphasized that there is lack of empirical data on organization collaboration to promote telemedicine adoption and diffusion in developing countries [13]. These gap need to be addressed by examining the potential of various organizational factors in facilitating telemedicine adoption in developing countries.

\section{Concepts underlying the theoretical background}

In this section of the paper, theories and models relating to innovation adoption and organization collaboration will be discussed. Technology Acceptance Model (TAM), Innovation Adoption
Theory (IDT) [14] and open innovation [15] have been utilized to discuss technology adoption.

Technology innovation adoption is the decision of innovation potential users to make full use of an innovation as the best course of action available. Diffusion is the process by which an innovation is communicated or spread through certain channels over time among the members of a social system. Consequently, diffusion of healthcare technological innovation such as telemedicine would permit decentralization of work where patient care services offered at national level are devolved to community level [6].

With the devolution of healthcare services aided by the adoption and diffusion of healthcare innovations such as telemedicine, the medical practitioners located at the national hospitals are able to attend to patients located in community hospitals without the need of any travel arrangements. However, the rate of adoption and diffusion of technological innovations within the healthcare sector is affected by various factors. According to [16], healthcare stakeholders influence the speed of adoption of these technologies. A blockage by any of the stakeholders to adopt the technology slows the entire progress of the innovation process.

Moreover, various scholars claim that the perceived attributes of an innovation have a great impact on the rate of absorption and diffusion of an innovation. The next section points out some of the attributes of an innovation especially in healthcare sector that influence the adoption and diffusion of healthcare technological innovations.

Additionally, open innovation is where organizations use internal and external ideas to accelerate the emergence of new technologies [17]. The organization collaborates with various organizations for idea generation. Although open innovation enable sharing of internal and external ideas with other organizations, the resource commitment in executing new technologies is mainly an individual tasks carried out by the organization adopting the new technology. Therefore, organizations executing costly innovative projects could need external sustainable sources of funding [18].

\section{Proposed conceptual framework for telemedicine adoption}

Organization collaboration has been claimed to facilitate telemedicine adoption in developing countries [7], [13], [15]. However, empirical studies on organization collaboration to facilitate telemedicine adoption and diffusion in developing countries is claimed to be lacking [11], [13].

To provide an overview on the benefits of organization collaboration in facilitating 
telemedicine adoption, a conceptual framework was developed from the extant literature (see Figure 2).

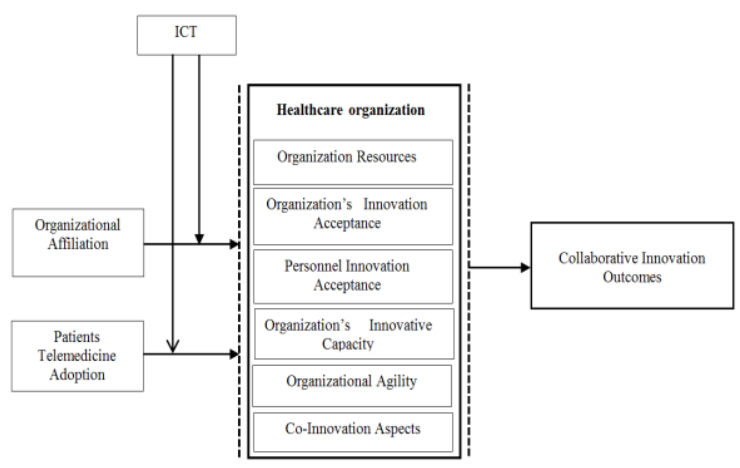

Figure 2. Research framework for telemedicine adoption through organization collaboration

Factors selected to investigate the role of organization collaboration in facilitating telemedicine adoption were extracted from technology acceptance model (TAM), innovation diffusion theory (IDT) and open innovation theory (OIT) which includes: Organization ICT infrastructure, organization affiliation, patient telemedicine adoption, organization resources, organization innovation acceptance, personnel innovation acceptance, organization innovativeness, organization agility and collaborative innovation aspects.

\subsection{Conceptual framework factors}

ICT infrastructure: ICT is related to making use of science and technology to organize the obtained information [19]. Organizations collaborative innovations heavily rely on internet based technologies [20].

Organization affiliation: One goal of collaboration is to enable innovation. It is argued that the implementation of e-health services requires multidisciplinary collaboration [21].

Patient telemedicine adoption: Technology acceptance is composed of attitude and behaviour. Attitude acceptance is a permanent cognitive and affective orientation of perception whereas behavioural readiness is the actual use or lack of use of the technology [22].

Organization resources: Assets that an organization owns. Availability of resources such as human, funds and technology influence the rate of adoption of eHealth technology [23].

Organization innovation acceptance: The current use of a system or technology and intentions to continue to use the system in the future [24]. According to [25], telemedicine implementation may not succeed fully without widespread acceptance of its applications.

Personnel innovation acceptance: Organization's personnel play an important role in influencing the adoption and diffusion of an innovation. In a study on organizational readiness to technology adoption, it was argued that technology end users must be considered before implementing new technologies [25].

Organization innovative capacity: [26] defines innovation capacity as the continuous improvement of the overall capability of an organization to generate innovation for developing new products and services to meet the currents demand. Furthermore, it is argued that an organization can improve its capacity to innovate through collaboration with other similar organizations.

Organization agility: Organizational agility is organization's ability to deal with changes that often arise unexpectedly via rapid and innovative responses that exploit changes as opportunities to grow and prosper [16].

Collaborative innovation aspects: Collaborative innovation is a platform where new ideas or approaches from various organizations are applied differently to create new value or experience [27]. When organizations decide to co-innovate, they enter into contracts with each other and agree on the distribution of the costs and the revenues of the coinnovation processes [28].

Collaborative innovation outcomes: Innovation outcomes can be examined in two dimensions: internal innovation outcomes and external innovation outcomes. The internal innovation outcomes are the operational benefits achieved within the healthcare organization. External innovation outcomes are benefits achieved in delivering healthcare services to the patients.

Integrating these factors will provide a platform to examine the benefits of healthcare organizations collaboration to facilitate telemedicine adoption.

\section{Methodology}

This paper presents a framework to examine healthcare organization collaboration factors which addresses a knowledge gap in terms of understanding which organizational factors and innovation practices influence organization collaboration in facilitating telemedicine adoption.

\subsection{Sample selection}

A three-month field study was carried out between January through March 2015 which focused on Kenyan healthcare hospitals located in Eastern Kenya. Research approval was obtained from Brunel University research ethics committee and Kenyan National Commission for Science, Technology and Innovation (NACOSTI).

Since engaging all members of a population in a study is not practical [29], convenience sampling and snow balling sampling techniques were used to identify the participating respondents. Convenience sample is a sample that is available by the virtue of 
its accessibility [30] whereas snowballing or networking is a form of convenience sampling where sample elements are identified by successive respondents within the organization or target group [31]. Snowballing and convenient sampling are appropriate in healthcare sector to minimize the chances of low survey response rates reported in healthcare industry [32].

\subsection{Study sample profile}

Structured questionnaires were self-administered to 186 healthcare practitioners in 50 healthcare organizations sampled. According to the Kenyan healthcare system, the hospitals are geographically grouped into four categories namely national, provincial, county and healthcare centres which also define the hospital size. National hospitals are the largest in size whereas healthcare centres are the smallest in size. Table 1 shows the sample profile of this study.

Table 1. Study sample profile

\begin{tabular}{|l|l|c|c|}
\hline \multicolumn{2}{|c|}{ Characteristic $\boldsymbol{n}=177$} & Frequency & $\%$ \\
\hline \multirow{2}{*}{$\begin{array}{l}\text { Organization } \\
\text { ownership }\end{array}$} & Private & 75 & 42.4 \\
\cline { 2 - 4 } & Government & 102 & 57.6 \\
\hline \multirow{3}{*}{$\begin{array}{l}\text { Geographic } \\
\text { coverage }\end{array}$} & National & 21 & 11.9 \\
\cline { 2 - 4 } & Provincial & 15 & 8.5 \\
\cline { 2 - 4 } & County & 90 & 50.8 \\
\cline { 2 - 4 } & Health centre & 51 & 28.8 \\
\hline \multirow{3}{*}{$\begin{array}{l}\text { Past } \\
\text { collaborative } \\
\text { projects }\end{array}$} & None & 22 & 12.4 \\
\cline { 2 - 4 } & $1-3$ & 124 & 70.1 \\
\cline { 2 - 4 } & $4+$ & 31 & 17.5 \\
\hline
\end{tabular}

In this study, all levels of hospitals were included in the sample. At the end of the field study, 9 questionnaires were not returned. The remaining 177 questionnaires were confirmed to be usable for further analyses.

\subsection{Use of SPSS software for analyses}

Statistical relationship between the two model factors examined in this paper (organization affiliation and organization collaborative innovation aspects) was examined using SPSS software. Firstly, the reliability test to measure the internal consistency of the model factors was determined using SPSS software. Cronbach alpha $(\alpha)$ is widely used to determine the internal consistency of test items before proceeding with any other statistical analyses. A value greater than 0.70 is recommended for a main field study although values ranging 0.50 to 0.69 are acceptable for preliminary studies. However, values greater than 0.90 may reflect unnecessary duplication of content across items and point more to redundancy than to homogeneity as they are testing the same question but in a different pretext. Therefore, a maximum Cronbach alpha value of 0.90 has been highly recommended [33]. Table II show the reliability test results of the model factors used in this research.

Table 2. Reliability test for model factors

\begin{tabular}{|l|c|}
\hline \multicolumn{1}{|c|}{ Test factor (n=177) } & $\boldsymbol{\alpha}$ \\
\hline ICT Infrastructure (ICT) & 0.840 \\
\hline Organizational Affiliations (OrgAff) & 0.792 \\
\hline Patient TM Adoption (PatTMAdp) & 0.791 \\
\hline Organization Resources (OrgRes) & 0.813 \\
\hline Organization Innovation Acceptance (OrgInnAcc) & 0.810 \\
\hline Personnel Innovation Acceptance(PsnInnAcc) & 0.842 \\
\hline Organization Innovative Capacities (OrgInnAcc) & 0.831 \\
\hline Collaborative Innovation aspects (CoInno) & 0.782 \\
\hline Internal Outcomes (InOut) & 0.824 \\
\hline External Outcomes (ExOut) & 0.842 \\
\hline
\end{tabular}

The model factors have an acceptable level of Cronbach alpha $\alpha>0.70$, therefore, all factors were accepted for statistical analyses.

\section{Results}

An inter-correlation test (r) was run to determine the level of relationship existing between the model factors. It was noted that no cases of multicollinearity existed between the model factors (see Table 3). Multicollinearity $(r>0.90)$ is the existence of a high level of relationship between variables which presents difficulties in accessing the importance of individual factors under study.

A strong positive relationship existed between organization affiliation and: organization ICT infrastructure $(\mathrm{r}=0.621)$, organization resources $(\mathrm{r}=0.524)$, collaborative innovation aspects $(\mathrm{r}=0.524)$ and external innovation outcomes $(\mathrm{r}=0.522)$. Similarly, a strong positive relationship existed between organization collaborative innovation aspects and collaborative innovation external outcomes. Additionally, organization's ICT infrastructure presented a strong relationship with organization's innovative capacity $(\mathrm{r}=0.572)$. However, patient telemedicine adoption presented a small relationship with all model factors $(r<0.29)$.

Also, organizations with highly developed ICT infrastructure were observed to be more innovative than those with less developed ICT infrastructure (see Figure 3). ICT infrastructure was dichotomized into two groups namely low ICT infrastructure and high ICT infrastructure. Scores with 3 and below were classified as low ICT infrastructure whereas those with 4 and above were classified as high ICT infrastructure. 


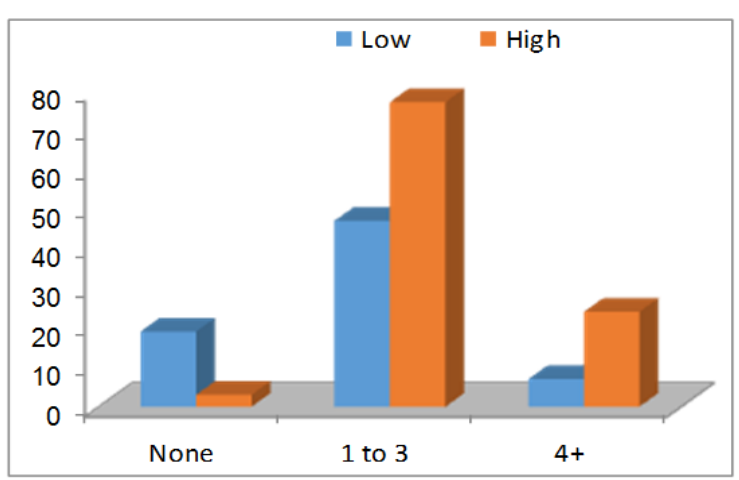

Figure 3. Collaborative innovation project based on level of ICT infrastructure

Similarly, private owned organizations were observed to be more innovative than government owned organizations (see Figure 4). This was determined using the number of collaborative innovative projects carried out by the organizations.

Furthermore, Analyses of variance test (ANOVA) was used to examine the difference existing in collaborative innovation outcomes, ICT infrastructure and organization agility basing on healthcare geographic coverage.

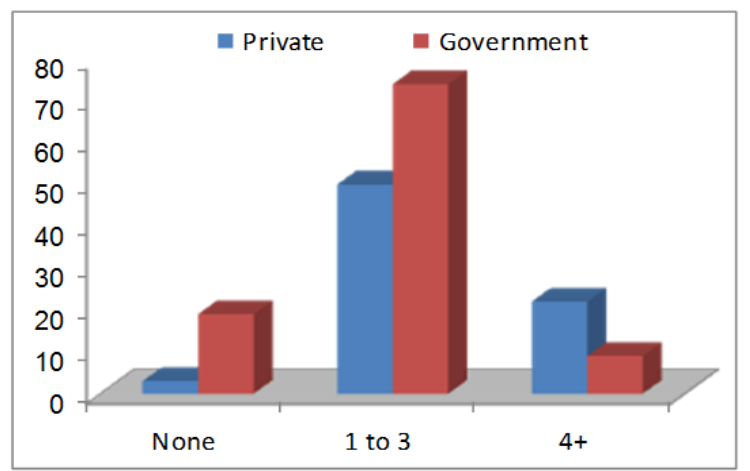

Figure 4. Collaborative innovation projectbased on organization ownership

It was observed that a significant difference in internal collaborative innovation outcomes existed between various organizations although no significant difference existed between national and provincial hospitals (see Table 4). However, no significant difference existed for external collaborative innovation outcomes using this basis in this study.

Table 3. Pearson's correlation matrix

\begin{tabular}{|l|c|c|c|c|c|c|c|c|c|}
\hline \multicolumn{1}{|c|}{ Variables } & P1 & P2 & P3 & F1 & F2 & F3 & F4 & F5 & F6 \\
\hline P1 OrgAff & 1 & & & & & & & & \\
\hline P2 PatTMadp & 0.015 & 1 & & & & & & & \\
\hline P3 ICT & $0.621^{* *}$ & $0.224^{* *}$ & 1 & & & & & & \\
\hline F1 OrgRes & $0.524^{* *}$ & 0.009 & $0.252^{* *}$ & 1 & & & & & \\
\hline F2 OrgInnAcc & $0.354^{* *}$ & $0.123^{*}$ & $0.412^{* *}$ & $0.529^{* *}$ & 1 & & & & \\
\hline F3 PsnInnAcc & 0.042 & 0.062 & $0.325^{* *}$ & $0.172^{* *}$ & $0.402^{* *}$ & 1 & & & \\
\hline F4 OrgInnCap & $0.372^{* *}$ & 0.021 & $0.572^{* *}$ & $0.459^{* *}$ & $0.442^{* *}$ & $0.342^{* *}$ & 1 & & \\
\hline F5 OrgAg & $0.425^{* *}$ & 0.042 & $0.315^{* *}$ & $0.447^{* *}$ & $0.352^{* *}$ & $0.384^{* *}$ & $0.322^{* *}$ & 1 & \\
\hline F6 CoInno & $0.524^{* *}$ & 0.062 & $0.411^{* *}$ & $0.303^{* *}$ & $0.259^{* *}$ & $0.224^{* *}$ & $0.382^{* *}$ & $0.512^{* *}$ & 1 \\
\hline O1 InOut & $0.412^{* *}$ & 0.082 & $0.412^{* *}$ & $0.487^{* *}$ & $0.421^{*}$ & $0.346^{* *}$ & $0.295^{* *}$ & $0.452^{* *}$ & $0.314^{* *}$ \\
\hline O2 ExOut & $0.522^{* *}$ & 0.102 & $0.392^{* *}$ & $0.542^{* *}$ & $0.292^{* *}$ & 0.011 & $0.341^{* *}$ & $0.462^{* *}$ & $0.512^{* *}$ \\
\hline
\end{tabular}

Table 4. Collaborative innovation outcomes basing on geographic

\begin{tabular}{|c|c|c|c|c|}
\hline \multicolumn{3}{|c|}{ Geographic coverage } & $\begin{array}{c}\text { Mean } \\
\text { Difference }\end{array}$ & Sig. \\
\hline \multirow{12}{*}{$\begin{array}{l}\text { Internal } \\
\text { outcome }\end{array}$} & \multirow[t]{3}{*}{ National } & Provincial & 0.111 & 0.080 \\
\hline & & County & 0.041 & 0.010 \\
\hline & & $\begin{array}{l}\text { Health } \\
\text { centre }\end{array}$ & 0.052 & 0.000 \\
\hline & \multirow[t]{3}{*}{ Provincial } & National & -0.111 & 0.080 \\
\hline & & County & -0.070 & 0.011 \\
\hline & & $\begin{array}{l}\text { Health } \\
\text { centre }\end{array}$ & -0.059 & 0.010 \\
\hline & \multirow[t]{3}{*}{ County } & National & -0.041 & 0.010 \\
\hline & & Provincial & 0.070 & 0.011 \\
\hline & & $\begin{array}{l}\text { Health } \\
\text { centre }\end{array}$ & 0.012 & 0.031 \\
\hline & \multirow{3}{*}{$\begin{array}{l}\text { Health } \\
\text { centre }\end{array}$} & National & -0.052 & 0.000 \\
\hline & & Provincial & 0.059 & 0.010 \\
\hline & & County & -0.012 & 0.031 \\
\hline
\end{tabular}

Significant at: $\mathrm{P}<0.05$
Similarly, a significant difference existed in organizations agility. Majority of national and provincial hospitals were observed to be more agile than county and healthcare centres (see Figure 5).

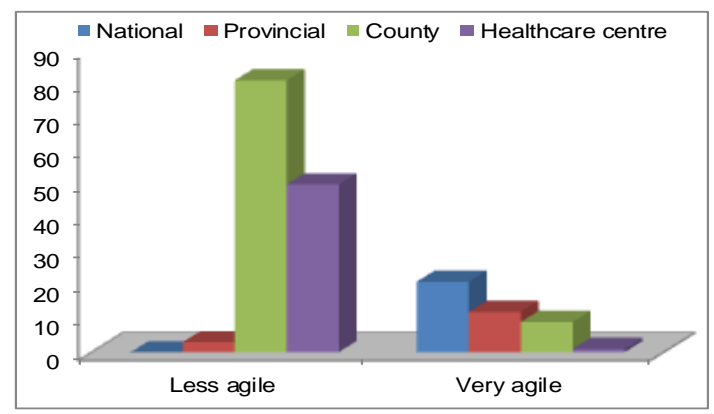

Figurte 5. Organization agility based on geographic coverage 
However, no significant difference existed in organization agility between national and provincial hospitals. The greatest difference existed between national hospitals and healthcare centres with a significant value of 0.000 (see Table 5).

Table 5. Organization agility basing geographic coverage

\begin{tabular}{|l|l|c|c|}
\hline \multicolumn{2}{|c|}{ Geographic coverage } & $\begin{array}{c}\text { Mean } \\
\text { Difference }\end{array}$ & Sig. \\
\hline \multirow{4}{*}{ National } & Provincial & -0.103 & 0.164 \\
\cline { 2 - 4 } & County & -0.044 & 0.003 \\
\cline { 2 - 4 } & Health centre & -0.114 & 0.000 \\
\hline Provincial & County & 0.059 & 0.036 \\
\cline { 2 - 4 } & Health centre & -0.011 & 0.001 \\
\hline County & Health centre & -0.070 & 0.040 \\
\hline
\end{tabular}

Significant at: $\mathrm{P}<0.05$

Also, a significant difference in the level of ICT infrastructure existed between various organizations where national and provincial hospitals presented a higher level of ICT infrastructure when compared to county and healthcare centres (see Figure 6).

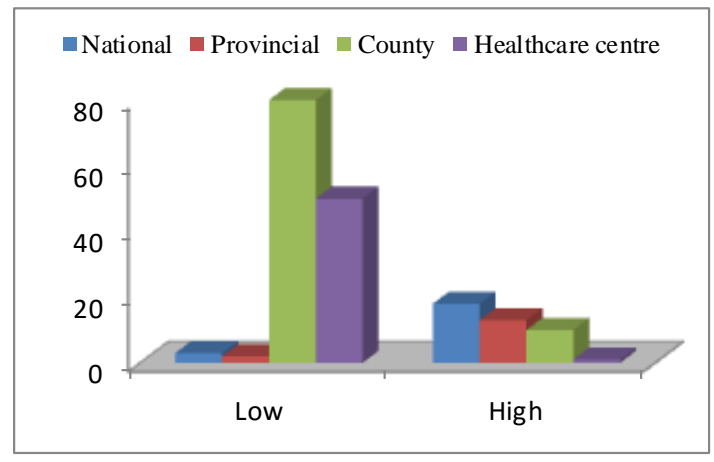

Figure 6. Organization level of ICT infrastructure basing on geographic coverage

However, no significant difference existed between national and provincial hospitals in terms of the level of ICT infrastructure (see Table 6).

Table 6. Organization ICT infrastructure basing on geographic coverage

\begin{tabular}{|l|l|c|c|}
\hline \multicolumn{2}{|c|}{ Geographic coverage } & $\begin{array}{c}\text { Mean } \\
\text { Difference }\end{array}$ & Sig. \\
\hline \multirow{4}{*}{ National } & Provincial & 0.319 & 0.693 \\
\cline { 2 - 4 } & County & 0.249 & 0.005 \\
\cline { 2 - 4 } & Health centre & 0.192 & 0.000 \\
\hline Provincial & County & -0.071 & 0.031 \\
\cline { 2 - 4 } & Health centre & -0.127 & 0.014 \\
\hline County & Health centre & -0.057 & 0.021 \\
\hline
\end{tabular}

\section{Discussion}

From this study, organization collaboration was found to have a positive effect on organization resources. These results are consistent with previous studies which found out that organization partnership especially in state owned organizations opens innovation cycle to various actors and taps innovation resources across borders. This study further highlights the importance of collaboration between private and public healthcare organizations.

It was observed that private owned healthcare organizations have a higher level of ICT infrastructure when compared to government owned healthcare organizations. This is claimed to have contributed to the high level of innovativeness of the private owned healthcare organizations. A study on organization innovation highlighted that private healthcare organizations are more likely to innovate than public hospitals whose mission as a provider of last resort restrains their resources thus limiting their innovative capacity [34].

Within the context of healthcare personnel innovation acceptance, it was observed that organization affiliation does not influence personnel's willingness to adopt healthcare technological innovation. The results are consistent with previous studies where it as observed that the personnel's level of competencies on ICT influenced the adoption of healthcare technologies [35]. Furthermore, the results of this study showed that the innovativeness of healthcare organization basing on the geographic location (which defines the organization size) differed greatly. National and provincial hospitals were found to be more agile than county hospitals and healthcare centres. The difference in agility between national and provincial hospitals was not very significant. Also, the level of ICT infrastructure between the four categories namely national, provincial, county and healthcare centres differed greatly. National hospital had the highest level of ICT infrastructure when compared to provincial, county and healthcare centres. Taking into account the results of this study, a rich understanding of the importance of healthcare organization collaboration can be fully realized in attempt to expedite the adoption of telemedicine in developing countries.

\section{Conclusion}

Despite large number of studies on barriers to telemedicine adoption in developing countries, high quality evidence on how to facilitate telemedicine adoption in developing countries is still lacking. Although extant literature has highlighted that organization collaboration can facilitate telemedicine adoption, studies with organizational designs on how organization collaboration can facilitate telemedicine adoption is lacking. Therefore, studies with rigorous designs are needed to examine organizational factors and innovation practices influencing organization collaboration in facilitating telemedicine adoption.

The regression analysis of this survey showed that organization affiliation is highly influenced by the status of organization's ICT infrastructure. Furthermore, organizations with a high level of ICT infrastructure were more innovative than the counterparts with low level of ICT infrastructure. 
All the organizational model factors were supported and explained $46.5 \%$ of the variance in collaborative innovation internal outcomes. Similarly, all the organizational model factors except personnel innovation acceptance were supported and explained $53.2 \%$ of the variance in collaborative innovation external outcomes. The study produced useful insights into understanding the importance of organization collaboration in facilitating telemedicine adoption in developing countries.

\section{Acknowledgment}

We acknowledge the respondents who kindly gave their time to participate in this study. We also acknowledge that an earlier version of this material was presented in a conference at the International Conference on Information Society (i-Society 2015), held on 9th to 11th November 2015, London, UK.

\section{References}

[1] Vitacca, M., Bianchi, L., Guerra, A., Fracchia, C., Spanevello, A., Balbi, B. and Scalvini, S. (2009). Teleassistance in chronic respiratory failure patients: a randomised clinical trial. European Respiratory Journal, 33 (2), pp. 411-418.

[2] Demiris, G. (2003). Integration of Telemedicine in Graduate Medical Informatics Education. Journal of the American Medical Informatics Association, 10(4), pp. 310-314.

[3] Strehle, E. and Shabde, N. (2006). One hundred years of telemedicine: does this new technology have a place in paediatrics? Archives of Disease in Childhood, 91(12), pp. 956-959.

[4] Zundel, K. (1996). Telemedicine: history, applications, and impact on librarianship. Journal of the medical library association, 84 (1), pp. 71-79.

[5] World Health Organization (1997). A health telematics policy in support of WHO'S Health-for-All Strategy for Global Health Development. Global Observatory for eHealth. 1st edn. Geneva: WHO Press.

[6] Heinzelmann, P., Lugn, N. and Kvedar, J. (2005). Telemedicine in the future. Journal of Telemedicine and Telecare, 11(8), pp. 384-390.

[7] Androuchko, L. and Nakajima, I. (2004). Developing countries and e-health services. Proceedings of IEEE 6th international workshop, June 28-29, Geneva, pp. 211 214.

[8] Wootton, R. (2008). Telemedicine support for the developing world. Journal of Telemedicine and Telecare, 14 (3), pp. 109-114.

[9] Harnett, B. (2006). Telemedicine systems and telecommunications. Journal of Telemedicine and Telecare, 12 (4), pp. 4-15.
[10] Hjelm, N. (2005). Benefits and drawbacks of telemedicine. Journal of telemedicine and telecare, 11(2), pp. 60-70.

[11] Jakobsen, N., Jensen, L. and Kayser, L. (2014). Collaborative efforts are needed to ensure proper knowledge dissemination of telemedicine projects. Danish medical journal, 61(9), pp. 4896-4896.

[12] Goes, J. and Park, S. (1997). 'Inter-organizational links and innovation: The case of hospital services. Academy of management journal, 40 (3), pp. 673-696.

[13] Bommert, B. (2010). Collaborative innovation in the public sector. International Public Management Review, 11(1), pp. 15-33.

[14] Rogers, E. (2003) Diffusion of Innovation. 5th edn. New York: Free press.

[15] Chesbrough, H. (2003) Open Innovation: The new imperative for creating and profiting from technology. Boston: Havard Business School Press.

[16] Lu, Y. and Ramamurthy, K. (2011). Understanding the link between information technology capability and organizational agility: an empirical examination. MIS quarterly, 35 (4), pp. 931-954.

[17] Chesbrough, H., Vanhaverbeke, W. and West, J. (2006) Open Innovation: Researching a New Paradigm. Oxford: Oxford University Press.

[18] Baldwin, C. and Hippel, V. (2011). Modelling a Paradigm Shift: From Producer Innovation to User and Open Collaborative Innovation. Organization Science, 22 (6), pp. 1399-1417.

[19] Yeganegi, K. and Azar, M. (2012). The Effect of IT on Organizational Agility. In Proceedings of the International Conference on Industrial Engine, July 03 06, Turkey, pp. 2537-2544.

[20] Michaelides, R., Morton, S. and Liu, W. (2013). A framework for evaluating the benefits of collaborative technologies in engineering innovation networks. Production Planning \& Control, 24 (3), pp. 246-264.

[21] Picard, W. and Rabelo, R. (2010). Engagement in collaborative network. Production Planning and Control, 21 (2), pp. 101-102.

[22] Meyer, J. (1997). The acceptance of visual information in Management. Journal of Information and Management, 32 (6), pp. 275-287.

[23] Perez, M., Sánchez, A., Carnicer, P. and Jiménez, M. (2004). A technology acceptance model of innovation adoption: the case of teleworking. European Journal of Innovation Management, 7 (4), pp.280 - 291.

[24] Agarwal, R. and Prasad, J. (1997). The Role of Innovation Characteristics and Perceived Voluntariness in the Acceptance of Information Technologies. Decision Sciences, 28 (3), pp. 557-582. 
[25] Jennett, P., Yeo, M., Pauls, M. and Graham, J. (2009). Organizational readiness for telemedicine: implications for success and failure. Journal of Telemedicine and Telecare, 9(2), pp. 27-30.

[26] Szeto, E. (2000). Innovation capacity: working towards a mechanism for improving innovation within an inter-organizational network. The TQM Magazine, 12(2), pp. $149-158$.

[27] Lee, S., Olson, D. and Trimi, S. (2012). Coinnovation: convergenomics, collaboration, and cocreation for organizational values. Journal of Management History, 50(5), pp. 817-831.

[28] Bossink, G. (2002). The development of coinnovation strategies- stages and interaction patterns in interfirm innovation. Journal R\&D Management, 32(4), pp. 311-320.

[29] Gill, J. and Johnson, P. (2002) Research Methods for Managers. 3rd edn. London: Sage.

[30] Saunders, M., Lewis, P. and Thornhill, A. (2012) Research methods for business students, 6th edn. Harlow: Prentice Hall.

[31] Bryman, A. and Bell, E. (2015) Business research methods. New York: Oxford university press.

[32] Wu, J., Wang, S. and Lin, L. (2007). Mobile computing acceptance factors in the healthcare industry: A structural equation model. International journal of medical informatics, 76 (1), pp. 66-77.

[33] Streiner, D. (2003). Starting at the beginning: an introduction to coefficient alpha and internal consistency. Journal of personality assessment, 80 (1), pp.99-103.

[34] Torchia, M., Calabro, A. and Morner, M. (2015). Public-Private Partnerships in the Health Care Sector: A systematic review of the literature. Public Management Review, 17(2), pp. 236-261.

[35] Damanpour, F. (1991). Organizational innovation: A meta-analysis of effects of determinants and moderators. Academy of management journal, 34 (3), pp. 555-590. 